\title{
A ÉTICA DA CRENÇA: UMA DEFESA MODERADA DA POSIÇÃO INDICIÁRIA
}

\author{
THE ETHICS OF BELIEF: A MODERATE DEFENSE OF THE EVIDENTIALIST \\ POSITION
}

EROS MOREIRA DE CARVALHO ${ }^{1}$

Universidade Federal do Rio Grande do Sul (UFRGS) - Brasil

eros.carvalho@ufrgs.br

\begin{abstract}
RESUMO: Neste artigo, articulo e critico os dois principais argumentos apresentados por Clifford em favor da norma de que é ilegítimo crer com base em evidência insuficiente. O primeiro argumento apela para o valor instrumental da crença, e o segundo apela para o nosso interesse intrínseco na verdade. Ambos os argumentos trazem à tona a relevância de fatores morais e sociais para a determinação de normas da crença. Eu sustento que o primeiro argumento é insuficiente para estabelecer a norma de Clifford em geral. Crenças que não são meios para ações ficam de fora do escopo do primeiro argumento. O segundo argumento tem um alcance mais abrangente. Contudo, ele pode ser bloqueado se o agente segue uma norma intelectualista que visa insular as crenças injustificadas do restante da sua vida cognitiva e ativa. É uma questão empírica se agentes humanos são capazes de seguir essa norma. Defendo uma reformulação da norma de Clifford, incluindo alguns parâmetros que influenciam a suficiência dos indícios. Por fim, fatores morais ou prudenciais podem afetar a legitimidade da crença. É legítimo crer sem indícios suficientes apenas em casos especiais, quando o agente insula a crença injustificada, ou quando o bem que advém da crença sobrepuja os malefícios da credulidade.
\end{abstract}

PALAVRAS-CHAVE: A ética da crença. Justificação epistêmica. Agência epistêmica. William Clifford. William James.

ABSTRACT: In this paper, I articulate and discuss Clifford's two main arguments in favor of the norm which renders illegitimate those beliefs which are based on insufficient evidence. The first argument appeals to the instrumental value of belief, and the second appeals to our intrinsic interest in truth. Both arguments bring to the fore the relevance of moral and social factors to determine norms for belief. I maintain that the first argument is insufficient to establish Clifford's norm in general. Beliefs that are not a means to an action fall outside the scope of the first argument. The second argument has a wider scope. However, it can be undermined if the agent follows an intellectualized norm that aims to protect the rest of her cognitive and active life from her unjustified beliefs. It's an empirical matter whether a human agent is able to follow this norm. I defend the claim that Clifford's norm should be reformulated, including some parameters that have influence on the sufficiency of evidence. Finally, prudential and moral factors can affect the legitimacy of belief. It's legitimate to believe without sufficient evidence only in special cases, when the agent insulates the unjustified belief, or when the good that results from believing surpasses the harms yielded by credulity.

KEYWORDS: The ethics of belief. Epistemic justification. Epistemic agency. William Clifford. William James.

\footnotetext{
${ }^{1}$ Professor da Universidade Federal do Rio Grande do Sul (UFRGS).
} 


\section{INTRODUÇÃO}

Você está participando de uma conversa quando, após fazer uma alegação, o seu interlocutor afirma que pensa exatamente o oposto do que você disse. Dependendo do quão dispostos vocês estão a discutir, razões ulteriores de ambas as partes podem ser demandadas e a discussão prossegue. Não havendo essa disposição no momento, ambos podem dar de ombros e atenuar suas respectivas declarações dizendo que as têm apenas como suas opiniões. Não há nada de grave nisso, já que nem sempre temos tempo ou estamos com vontade de discutir. Às vezes só queremos jogar conversa fora, sem confronto, sem ter de pensar muito. Nessas ocasiões, dar um passo atrás e recalibrar a sua afirmação como uma mera opinião para postergar o confronto é sinal também de respeito ao intelecto do interlocutor. Manter a alegação implicaria passar a mensagem de que, independentemente do que o interlocutor pense, você está certo e ele, errado.

A situação torna-se preocupantemente grave se a atitude de se recusar a dar razões ou de considerar razões contrárias é generalizada, como se ter uma crença ou opinião fosse sempre uma questão de gosto, cada um tem a sua e ninguém tem nada a ver com isso. Podemos conversar para trocar opiniões, como quem conversa e explicita seus gostos e, com alguma curiosidade, toma conhecimento dos gostos dos outros, mas não somos obrigados a defender as nossas opiniões. Opinião ou crença, neste cenário, é um assunto sempre privado, uma questão pessoal. Assim, exigir de alguém razões para ter as opiniões que tem é, na melhor das hipóteses, inapropriado e, na pior, ofensivo e desrespeitoso.

A compreensão da crença como uma questão pessoal ou de gosto não parece ser compatível com a própria natureza da crença. Há algo de tão profundamente equivocado nessa compreensão que quem a sustenta ou manifesta se sujeita à franca acusação de irracionalidade. A crença tem como fim a verdade, ela é uma atitude proposicional, isto é, ela é o ato mental de tomar uma proposição como verdadeira. Por ter um fim, uma crença pode ser avaliada quanto a quão bem ela visa a verdade. Alguém que trate as suas crenças como uma questão pessoal ou de gosto não reconhece que elas possam ser criticadas ou avaliadas. Ao contrário, ela pensa que suas crenças, como seus gostos, são uma questão de capricho e fortuna. Elas podem e provavelmente têm causas, que seu portador provavelmente desconhece, mas não respondem ou precisam responder absolutamente a nenhuma razão, elas não são criticáveis. Nesse sentido, são caprichosas. Resultam da fortuna, pois seu portador não tem também nenhuma responsabilidade sobre elas. Ora, alguém que tenha essa atitude passiva em relação às proposições que acalenta não parece visar a verdade de modo algum. Em poucas palavras, não parece ser possível visar a verdade caprichosa e passivamente. Assim, seria irracional ter crenças e acalentar a compreensão da crença como uma questão pessoal ou de gosto. Para visar a verdade, isto é, de um modo responsável e ativo, é preciso que se possa avaliar essa visada, é preciso, portanto, que se possa dizer que o agente visa a verdade em conformidade com normas mínimas da crença, normas que nos permitem avaliar quão bem o agente visa a verdade. Na literatura, essas normas são chamadas de "normas epistêmicas". 
Um dos principais objetivos deste texto é discutir quais normas epistêmicas governam a crença.

Um segundo objetivo será inquirir se normas de outro tipo incidem também sobre a crença. Como as nossas ações estão fortemente conectadas às crenças, é possível que normas prudenciais e morais recaiam sobre as crenças ou exerçam algum tipo de pressão sobre elas. Por exemplo, pode ser socialmente prudente fomentar a confiança no outro mesmo na ausência de evidência de que o outro seja confiável. Pode ser moralmente requerido de um pai que ele acredite na inocência do seu filho mesmo se houver alguma evidência que torne seu filho suspeito. Se este for o caso, é importante que tenhamos clareza sobre como essas normas não-epistêmicas incidem sobre a crença e discutamos, em caso de conflito entre as normas, como ele pode ser equacionado.

\section{CRENÇA E AGÊNCIA}

Disse acima que a crença é o ato mental de tomar uma proposição como verdadeira. Essa formulação aproxima as crenças das ações. Essa aproximação precisa ser tomada com algum cuidado. Por um lado, ela adequadamente nos leva a enxergar a dimensão ativa do ato de crer e a compreender a responsabilidade que temos sobre as nossas crenças. Por outro lado, ela pode exagerar essa percepção a ponto de falsificar o próprio fenômeno da crença. A aproximação pode nos levar a pensar que somos livres para crermos no que quisermos apenas pelo exercício da vontade e que somos responsáveis por nossas crenças apenas porque elas estão absolutamente sob o nosso controle. ${ }^{2}$ No entanto, parece trivialmente falso que possamos sempre acreditar no que quisermos ou mesmo que esteja em nosso poder a qualquer momento tomar ou rejeitar qualquer proposição como verdadeira apenas pelo esforço da vontade. Neste momento, não posso simplesmente deixar de acreditar que há um computador na minha frente, que tenho duas mãos etc. Ou, ao contrário, não posso simplesmente crer que a lua é feita de queijo ou que a soma de duas notas de cinco reais perfaz cem reais. "Podemos afirmar qualquer dessas coisas, mas não temos de modo algum o poder de acreditar nelas" (JAMES, 2010, p. 142). Capacidades cognitivas como a percepção, a memória e a razão impõem ou rejeitam certas crenças de um modo que exclui a atuação da vontade.

Alguém poderia retrucar que com bastante engenho, mobilizando talvez argumentos céticos em alguns casos e dogmáticos em outros, seria possível apresentar razões para debilitar as crenças que são impostas por essas capacidades ou para reforçar aquelas que são rejeitadas por elas. Mas esse não seria um caso

\footnotetext{
${ }^{2} \mathrm{Na}$ literatura, essa posição é chamada de "voluntarismo doxástico". Algo próximo a essa posição foi defendido por Descartes. Ele sustenta que o erro, especialmente o do juízo, não se deve ao intelecto, mas à vontade que se precipita na afirmação de um conteúdo acerca do qual não temos clareza: "pelo intelecto sozinho não afirmo, nem nego coisa alguma, mas apenas percebo as ideias das quais posso fazer um juízo" (DESCARTES, 2004, p. 117). Só pela vontade afirmaríamos ou negaríamos alguma coisa. Críticas muito duras ao voluntarismo doxástico foram apresentadas por William Alston (1988).
} 
em que apenas pela vontade decidimos crer ou deixar de crer em uma proposição. Esse seria um caso em que recorremos à razão e ao raciocínio para fortalecer ou debilitar uma crença. Essa é uma estratégia que inclusive conta com o fato de que a razão é efetiva em impor e rejeitar certas crenças de um modo que exclui a atuação da vontade. O papel da vontade, nesse caso, está antes na mobilização da razão para se opor à imposição ou à rejeição de crenças por parte de outras capacidades ou pela própria razão. Esse ponto é importante, pois nos permite manter a aproximação entre crenças e ações sem a consequência indesejada apontada acima. Também no caso das ações é falso que a vontade possa atuar sobre cada parte do processo que compreende uma ação. Quando decido, por exemplo, levantar-me da cadeira, mobilizo uma série de capacidades motoras, as quais desencadearão os movimentos necessários para que eu consiga ficar de pé, mas é falso que eu possa, pela vontade apenas, estimular ou reprimir cada músculo em particular que é controlado pelas minhas capacidades motoras. Embora eu possa escolher me levantar me apoiando mais na perna esquerda que na direita, ou fazendo este ou aquele movimento com as pernas, não posso escolher quais músculos e tendões exatamente serão empregados. Nem por isso deixo de ser o autor da ação de me levantar e, portanto, de ser responsável por ela. O mesmo se passa com a crença. Embora a vontade não possa intervir no funcionamento interno de capacidades cognitivas como a percepção, a memória e a razão, pelo menos não em todos os seus aspectos, o resultado do emprego dessas capacidades cognitivas, a adoção ou rejeição de crenças, é obra do agente que mobilizou e exerceu essas capacidades. Assim, ao dizer que a crença é o ato de tomar uma proposição como verdadeira, não quero dizer que este ato é sempre o resultado do exercício da vontade apenas num instante do tempo, mas que, em muitos casos, ele resulta do emprego ou exercício que o agente faz das suas capacidades cognitivas. Não está excluída, por definição, a possibilidade do agente tomar uma proposição como verdadeira através da vontade.

Restam ainda algumas dificuldades, já que não foi dito nada de muito positivo ou informativo acerca de como o agente mobiliza as suas capacidades cognitivas e de como a sua vontade participa dessa mobilização. Às vezes, as capacidades cognitivas de um agente podem engendrar estados representacionais sem que ele as tenha mobilizado, assim como as capacidades motoras podem ser postas em operação, como na situação de um movimento reflexo, sem que o agente as tenha mobilizado. Em ambos os casos, os resultados do exercício dessas capacidades não são ações que possam legitimamente ser atribuídas ao agente. Os resultados, como foi dito, são respectivamente um estado representacional e um movimento reflexo, não crença e ação. Em outras situações, não é claro se o agente mobilizou ou exerceu as suas capacidades cognitivas, ou se elas foram postas em operação por causas e fatores que são estranhas a sua agência. Tomando um exemplo de Hume,

Consideremos o caso de um homem que se encontra dentro de uma gaiola de ferro pendente de uma alta torre. Ao olhar para o precipício embaixo dele, esse homem não pode se impedir de tremer, embora saiba que está perfeitamente seguro e que não cairá, pois tem experiência de que o ferro que o sustenta é sólido (HUME, 2009, 1.3.13.10). 
O homem em questão parece ter crenças contraditórias. Uma é implicada pelo seu conhecimento de que a gaiola é segura. Se interpelado, ele prontamente a explicitaria. A outra se manifesta pelo seu temor. Implicitamente, o homem parece crer que a gaiola é insegura, por isso treme. Se ambas as crenças podem ser atribuídas ao homem em questão, então teríamos um caso de irracionalidade. No entanto, não é evidente que o segundo estado mental deva ser um caso de crença, que ele resulte da mobilização das capacidades cognitivas do homem em questão. Em um caso normal de contradição, apontaríamos para o sujeito as suas crenças contraditórias e ele, após deliberação, concluiria qual delas tem suporte menor e a rejeitaria. No caso narrado por Hume, não parece que fazer o sujeito notar o conhecimento que ele tem de que a gaiola é segura vá atenuar o seu tremor. Esse tremor não parece ser sensível a razões. Situações como essa não são tão incomuns. Pense no caso do sujeito que sinceramente diz não ser racista, luta engajadamente contra o racismo sempre que a oportunidade surge, mas, sem perceber, manifesta, em um certo tipo de ocasião e apenas nesse tipo, atitudes racistas, ainda que não sejam flagrantemente racistas. Esse sujeito tem crenças contraditórias ou um dos estados desse sujeito não é um caso de crença? ${ }^{3}$ Essas atitudes obviamente precisam e devem ser reformadas ou suspensas, o agente é responsável por elas e, no caso em questão, ele prontamente se disporia a modificar essas atitudes se lhe chamassem a atenção para o fato, mas não parece que elas possam ser reformadas apenas pela reflexão e nem que, nesse caso, o agente seja tão reprovável, embora seja, quanto um outro que tem atitudes similares em função de crenças explicitamente racistas.

A discussão dessa dificuldade nos levaria muito longe e envolveria a solução de questões mais gerais relacionadas à natureza da crença, à agência epistêmica e ao livre-arbítrio. ${ }^{4}$ Aqui cabe apenas registrar que estou interessado no fenômeno da crença como um ato ou episódio de um agente cognitivo resultante da mobilização das suas capacidades cognitivas ou da sua vontade, atos ou episódios que o agente pode pelo menos em princípio modificar pela reflexão ou pela mobilização das demais capacidades cognitivas. Estados representacionais que são atribuídos a organismos que não exibem agência ou que, mesmo sendo atribuídos

\footnotetext{
${ }^{3}$ Para uma discussão acerca de se esses estados devem ou não contar como casos de crenças, veja Gendler (2008), Myiazono e Bortolotti (2014), e Frankish (2009). Note que o que está em discussão é a conexão entre crença e racionalidade. É possível que tenhamos crenças que são sistematicamente, e não apenas momentaneamente, resistentes a razões? A conexão se deve pelo fato de que a racionalidade parece ser um meio necessário para que a crença atinja o seu fim, a verdade. Isso não significa que ela tenha de estar baseada em razões, mas ao menos que não deveria sistematicamente ser insensível a razões ou indícios que o sujeito possui e sabe possuir. Estados do agente que estão desconectados da racionalidade, mas relevantes para a explicação da sua vida mental, receberiam uma classificação própria. Nesse debate, pode-se ainda defender que a racionalidade, entendida como sensibilidade a razões, não é sempre necessária para que a crença atinja o seu fim. Poderia haver, portanto, crenças irracionais epistemologicamente eficazes, veja Bortolotti e Miyazono (2016). Para uma discussão mais geral dos diferentes estados mentais que normalmente são referidos pelo termo "crença", veja Stevenson (2002). Ele distingue pelo menos seis tipos de estados.

${ }^{4}$ Há uma ótima discussão sobre a agência epistêmica e bastante crítica da sua possibilidade no capítulo "Freedom" de On Reflection (2012). Para uma visão mais positiva, veja o livro recente de Ernest Sosa (2015), especialmente o nono capítulo, "Epistemic Agency".
} 
a agentes, são sistematicamente resistentes e insensíveis a razões estão aquém do fenômeno que tenho em vista.

\section{A NORMA GERAL DA CRENÇA}

Já disse que a crença, em virtude de sua própria natureza, é incompatível com a atitude de tratá-la como uma questão pessoal. Isso significa que a atitude de um agente de tomar uma proposição como verdadeira deve poder ser avaliada à luz do seu fim, que é a verdade. Segue-se daí que há normas da crença, embora ainda não tenhamos entrado na discussão de quais são essas normas. Cabe agora, investigá-las e determiná-las com alguma precisão.

Em um artigo já clássico sobre o tema, Clifford propôs a seguinte norma geral da crença, que vou chamar de "INDÍCIO": "É sempre incorreto, em todo o lado, para qualquer pessoa, acreditar seja no que for com base em indícios insuficientes" (CLIFFORD, 2010, p. 180).

Há várias coisas que precisam ser esclarecidas nessa formulação. Primeiro, o que são indícios? Segundo, como determinamos a suficiência dos indícios? Terceiro, o que significa dizer que se crê com base em indícios, isto é, como baseamos a crença em indícios? Quarto, ainda que ninguém esteja isento de apresentar indícios suficientes, todas as pessoas, independente da sua formação ou especialização, devem crer com base nos mesmos indícios, ou devem pelo menos apresentar indícios com igual força epistêmica, isto é, indícios que suportem igualmente a verdade da crença acalentada? Vou responder a essas questões na medida em que discuto os argumentos apresentados por Clifford em favor da norma da crença INDÍCIO.

Clifford apresenta em favor de INDÍCIO basicamente dois argumentos: um que apela para o interesse instrumental que temos na verdade em função de nossos compromissos morais e sociais e um segundo que apela para o nosso interesse intrínseco na verdade, enquanto agentes cognoscentes. Como o primeiro argumento é formulado a partir de casos concretos, Clifford oferece ainda considerações e argumentos suplementares para estender a sua conclusão a todas as crenças de um agente.

O primeiro argumento basicamente é elaborado a partir da seguinte ideia: se nós nos importamos com algo, então nos importamos ou deveríamos nos importar em ter crenças verdadeiras acerca desse algo. Se nós nos preocupamos com o bem-estar dos outros, então devemos nos preocupar em ter crenças verdadeiras que apoiam cursos de ações que terão consequências para terceiros. E a razão para isso é muito simples: a verdade é útil,5 ela é especialmente útil para a boa ação. Vejamos um caso para ilustrar esse ponto. Suponha um técnico de aviação responsável pela manutenção de aviões. Toda vez que um avião pousa,

\footnotetext{
${ }^{5}$ Como coloca Harry Frankfurt, "As civilizações nunca avançaram de maneira saudável, e não podem avançar de maneira saudável, sem grandes quantidades de informação factual confiável. Tampouco podem prosperar se são cercadas por incômodas infecções de crenças errôneas" (FRANKFURT, 2007, p. 41).
} 
ele é responsável pela aplicação dos testes T1...T20 para averiguar se o avião continua íntegro e em condições seguras para o próximo voo. Eventualmente, um avião não passa em um dos testes e medidas apropriadas de reparação são tomadas pelo técnico. Imagine agora que um desses testes, digamos o T18, não apresentou resultado negativo em nenhum avião examinado pelo técnico. Chega um avião e técnico é alocado para testá-lo. Premido pelo tempo e pela consideração de que os aviões, na sua experiência, sempre passaram pelo teste T18, ele presume que esse avião também passará e ganha alguns minutos suspendendo a aplicação do T18. O técnico aplica os demais testes e o avião passa em todos, sendo então liberado para o próximo voo. Se interpelado, o técnico dirá que sinceramente acredita que o avião está seguro para o próximo voo. Mas estará ele justificado a assim acreditar?

Como falhas no avião durante o voo podem provocar a queda do mesmo, acarretando provavelmente a morte de muitas pessoas, a liberação de um avião para o voo deve estar amparada não em um palpite de que o avião está seguro, mas em uma crença bem justificada de que o avião está seguro. É verdade que o avião pode estar seguro e ainda assim cair, ou não estar seguro e ainda assim não cair. Contudo, dado o que sabemos acerca de aviões, voos, quedas de aviões etc.; as chances de que ele caia se não estiver seguro são muito maiores do que se estiver seguro. Afinal, os testes para verificar a sua segurança foram elaborados justamente para minimizar as chances de um avião cair. Se cair, será pela atuação de fatores não previstos ou irremediáveis. Se nos importamos com a vida das pessoas que estão no avião, então não podemos ser indiferentes quanto ao fato de o avião estar ou não seguro segundo os testes. A verdade sobre a questão importa e muito, tanto quanto nos importamos com a vida das pessoas embarcadas. Sendo assim, devemos preferir a crença justificada ao palpite. Reconhecemos que a crença do técnico de que o avião está seguro não é um mero palpite. Ele aplicou 19 testes no avião. Contudo, ele poderia ter aplicado 20 testes e ter uma crença ainda mais segura do que aquela que ele obteve. Estava ao seu alcance reunir mais indícios do que ele efetivamente reuniu. Mesmo tendo feito uma indução de que o avião passaria no teste T18, essa indução é fraca, limitada apenas à experiência de um único técnico. Os indícios que ela reúne são menos significativos do que os indícios reunidos pela aplicação do próprio teste T18. Ainda que fosse perder algum tempo, o técnico deveria ter aplicado o teste e apoiado a ação de liberar o avião em uma crença mais segura do que aquela que ele acabou formando ao negligenciar o teste T18. Ele expôs desnecessariamente ao risco as pessoas que embarcaram no avião. Assim, o técnico não estava justificado a crer como fez. Ele não zelou pela sua crença como deveria:

Quem desejar bem aos seus semelhantes nesta matéria guardará a pureza da sua crença com o fanatismo próprio de um zelo ciumento, para que a dada altura não recaia sobre um objeto indigno, ganhando uma mancha que jamais se poderá remover (CLIFFORD, 2010, p. 104).

É importante enfatizar que a preocupação com os semelhantes não é uma razão moral para o técnico crer que o avião está ou não está seguro. É uma razão 
moral para que o técnico se importe com a verdade de crenças que apoiarão cursos de ação que têm consequências para os seus semelhantes. E o ponto mais relevante: se importa de uma maneira que exige alguma garantia para a verdade dessas crenças. As crenças devem ser justificadas e a segurança que elas oferecem deve ser compatível com o que está em jogo. Caso contrário, o outro é exposto desnecessariamente ao risco, não sendo, assim, levado em consideração como deveria. Em se tratando da vida das pessoas, a segurança deve ser muito elevada, se não a mais elevada. Por isso mesmo, a crença do técnico, embora baseada em indícios, não foi suficientemente baseada em indícios. Se algo de menor importância estivesse em jogo, uma segurança menor seria suficiente. Razões morais não são indícios para crer, mas elas determinam ou nos auxiliam a determinar que quantidade de indícios ou que grau de indício é suficiente para crer.

\section{ESTENDENDO A NORMA INDÍCIO}

O argumento apresentado na seção 3 não é suficiente para sustentar INDÍCIO. Trata-se de um argumento baseado em casos particulares. Na melhor das hipóteses, ele pode ser generalizado para englobar as crenças que efetivamente apoiam cursos de ação que têm consequências para terceiros. Como INDÍCIO não se restringe a essas crenças, na verdade, INDÍCIO envolve qualquer crença, mais precisa ser dito para sustentar INDÍCIO. Uma primeira consideração seria a de generalizar o argumento para englobar crenças do agente que podem apoiar cursos de ação, ainda que, no momento em que foram adquiridas, não tivessem sido mobilizadas para apoiar qualquer curso de ação. Se essa extensão não for feita, corremos o risco de adquirir e fixar legitimamente crenças sem o apoio de indícios suficientes, já que, no momento, elas não apoiariam qualquer curso de ação. Quando a oportunidade para produzir ações com base nessas crenças surgisse, empregaríamos então crenças que estariam muito aquém da segurança necessária para responder ao que é colocado em jogo por essas ações. Por precaução, movida pela nossa preocupação com o bem-estar dos semelhantes, a extensão é bemvinda. Contudo, ela envolve uma dificuldade. Se, ao adquirir uma crença, não temos em vista um curso de ação que ela poderia apoiar, então não é claro quais indícios seriam suficientes para ela. No caso do técnico, estava claro que ele deveria aplicar todos os testes, pois o curso de ação em vista era o voo com passageiros. Se o curso de ação em vista fosse levar o avião para o "cemitério" de aviões ao lado do aeroporto, por terra, muito provavelmente os vinte testes não seriam necessários. Visto que não temos como saber de antemão quais ações as nossas crenças apoiarão ou poderão vir a apoiar, não é claro como determinar a suficiência dos indícios para crer nesses casos. Diante dessa dificuldade, uma versão mais fraca de INDÍCIO poderia ser defendida, uma versão que não exige indícios suficientes para crer, mas apenas indícios favoráveis. Outra opção seria exigir do agente entrever o curso de ação mais arriscado que pode ser apoiado na crença que ele adquire no momento para que, com base nessa ação, ele estimasse os indícios suficientes. A primeira opção parece ser muito fraca já que tornaria permissível acalentar qualquer crença desde que houvesse algum indício favorável 
a ela, por mais fraco que fosse, e vimos que, em algumas situações, como a do técnico, isso é insuficiente. A segunda parece exigir demais do agente, pois ele teria que pensar em possíveis ações e comparar o que elas colocam em jogo, o que intelectualizaria demais a aquisição permissível ou legítima da crença. Uma terceira posição conciliatória seria exigir indícios suficientes para as crenças que, no momento da aquisição, já se sabe quais cursos de ação elas apoiarão e, pelo menos, indícios favoráveis para as crenças que, no momento da sua aquisição, não se entrevê quais cursos de ação elas poderão vir a apoiar. Essa posição ainda teria a desvantagem apontada inicialmente. As crenças adquiridas agora com base apenas em indícios favoráveis poderiam no futuro apoiar cursos de ação sem responder ou dar a devida segurança ao que é colocado em jogo por essas ações. Podemos melhorar essa última posição estipulando um mínimo de indícios que garanta certa segurança para crenças que, no momento da sua aquisição, não se entrevê nenhum curso de ação baseado nelas e, ao mesmo tempo, adotar a política de reavaliar os indícios de uma crença já adquirida sempre que ela for mobilizada para uma ação em que muita coisa esteja em jogo.

Não vou me prolongar nessa discussão da extensão do primeiro argumento em favor de INDÍCIO. Como vimos, não é nada trivial sustentar o requisito da suficiência dos indícios para a totalidade das crenças de um agente. Nesse sentido, a norma INDÍCIO carece de alguma reformulação e mais adiante destacarei um outro ponto em relação ao qual a norma também precisa ser reformulada. Uma segunda dificuldade consiste em que a extensão proposta no parágrafo anterior envolve no máximo crenças que podem apoiar cursos de ação. E se houver crenças que, em princípio, são inertes do ponto de vista da ação? Ou crenças que, embora não sejam inertes do ponto de vista da ação, ensejam ações que não têm nenhuma consequência para terceiros? Em qualquer caso, mesmo que déssemos uma resposta satisfatória para a dificuldade anterior, a norma INDÍCIO não poderia ter por escopo a totalidade das crenças de um agente se houver crenças do primeiro ou do segundo tipo. Mas há crenças de algum desses tipos?

\section{CREnÇAS GRATUitas}

Alexandre Machado cita como exemplo de crença gratuita a sua crença de que uma pedra vista na beirada da estrada muitos anos atrás ainda se encontra lá (MACHADO, 2016). Uma crença gratuita é uma para qual o agente não tem nenhum indício favorável e que o agente sabe não contradizer qualquer outra crença sua para a qual ele tenha indícios favoráveis. É importante que não se trate de uma pedrinha de algumas gramas, pois, neste caso, sua crença estaria em conflito com a crença, que é presumível que ele tenha, de que pedrinhas desse tipo se movem pela força do vento gerado pela passagem de um caminhão. Mas suponhamos que seja uma pedra pesada e que, apesar de o Machado ter outras crenças que pudessem apoiá-la, e.g. a crença de que pedras muito pesadas não são movidas pela passagem de veículos e caminhões, ele acalenta a crença de que a pedra ainda está lá sem se apoiar em qualquer indício. Essa seria então uma crença gratuita para ele. 
Essa crença em particular é inerte do ponto de vista da ação? Pode ser o caso que Machado a acalente sem ter no horizonte qualquer curso de ação baseado nela. Todavia, não é difícil imaginar ações que possam se basear nessa crença. Pode-se propor ao agente que aposte na verdade da crença. Essa é uma estratégia geral para conectar crença e ação, e estimar ainda que grau de credibilidade o sujeito confere à proposição acreditada. Para que o Machado acredite que a pedra ainda se encontra no acostamento da estrada, ele tem de estar disposto a apostar alguma quantia na verdade da crença. O quanto ele apostará dependerá do quanto acredita nessa proposição. Se Machado não estiver disposto a apostar nem na verdade, nem da falsidade da proposição de que a pedra ainda se encontra no acostamento da estrada, então ele nem crê, nem descrê nessa proposição. A aposta é uma ação que se baseia na crença. Assim, parece difícil sustentar que haja crenças, por princípio, inertes do ponto de vista da ação, isto é, que não impliquem qualquer disposição a agir, nem mesmo a de apostar na verdade da proposição, muito embora ela possa ser acalentada sem que o agente tenha, no momento, qualquer ação no horizonte. Pode-se alegar que essa estratégia geral para conectar crença e ação não é suficiente para colocar a crença sob o escopo do primeiro argumento de Clifford, uma vez que a ação de apostar não tem necessariamente consequências para terceiros. Todavia, ela tem consequência para o próprio agente e na medida em que o agente se preocupa com o seu próprio bem-estar, ele tem uma razão para se importar com a verdade de proposições que tem ou podem ter consequências para o seu bem-estar.

Assim, talvez uma versão prudencial do argumento de Clifford possa ser elaborada. Se qualquer crença implica pelo menos a disposição de apostar na sua verdade, então todas as crenças têm, pelo menos, uma consequência para o bemestar do agente. Isso significa que o agente tem uma razão prudencial para se preocupar e se importar com a verdade das suas crenças. Resta saber se essa preocupação, como no caso moral, é suficiente para requerer que o sujeito tenha pelo menos indícios favoráveis para a sua crença. O bem-estar do outro, se afetado pelas ações de um agente, requerer que as crenças que apoiaram as suas ações estejam asseguradas, ou o agente poderá ser acusado de negligência epistêmica. Espera-se que o agente faça o seu melhor relativamente ao que está em jogo buscando indícios que sejam favoráveis e suficientes para a verdade dessas crenças. A situação não é completamente análoga quanto consideramos apenas o bem-estar do próprio agente. A negligência epistêmica consigo mesmo também é uma falta. Contudo, só será uma falta prudencial se o agente adquirir crenças que têm uma segurança aquém do bem-estar que o agente quer assegurar. O ponto é que o agente pode decidir arriscar o seu próprio bem-estar, se não completamente, pelo menos na medida em que não comprometa a sua autonomia. E se ele pode fazê-lo, então a aposta na verdade de uma crença, ainda que seja um indício da convicção subjetiva do agente e exija que ele tenha alguma, não exige do agente a posse de indícios favoráveis ou suficientes para a crença. A convicção subjetiva é um estado psicológico que expressa o grau de comprometimento que o agente tem com uma proposição, ele é distinto da posse de indícios favoráveis. Embora a convicção possa acompanhar a posse de indícios e, espera-se, seja normalmente um reflexo dela, no caso da aposta na verdade de uma proposição, a convicção 
subjetiva e a posse de indícios favoráveis podem muito bem estar apartadas. A aposta na verdade da crença depende da convicção subjetiva para mobilizar o agente a se dispor a arriscar o próprio bem-estar, de outro modo ele não teria a "coragem" suficiente para sustentar a aposta, mas não depende da posse de indícios favoráveis ou suficientes. Assim, não me parece que a versão prudencial do argumento de Clifford logre êxito.

Algumas considerações ainda quanto à extensão da versão moral do argumento de Clifford. Na ausência de um procedimento geral que conecte crença a ações que têm consequências para terceiros, não há como generalizar o argumento de Clifford para a totalidade das crenças de um agente. Talvez se possa alegar, a partir do holismo semântico, que como as crenças estão conectadas umas com as outras logica e conceitualmente, então qualquer crença que esteja assim conectada a uma outra que apoia diretamente cursos de ações que têm consequência para terceiros apoia também essas ações indiretamente. Se o apoio indireto não é dispensável, então requer-se indícios favoráveis das crenças que apoiam indiretamente curso de ações que têm consequências para terceiros tanto quanto se requer das que apoiam diretamente. Não vou seguir esse caminho, mas penso que ele pode ser elaborado para sustentar a conclusão de que qualquer crença de um agente, direta ou indiretamente, pode vir a apoiar um curso de ação que tem consequência para terceiros. Assim, todas as crenças de um agente são potencialmente abrangidas pelo argumento de Clifford. ${ }^{6}$ Não haveria espaço para crenças gratuitas, elas seriam ilegítimas.

Ainda assim, haveria como resistir a essa última conclusão. O primeiro argumento de Clifford apoia-se na ideia de que um curso de ação que tem consequência para terceiros deve apoiar-se em estados cognitivos seguros, isto é, que visem a verdade minimizando a possibilidade de engano. $O$ interesse pela verdade, nesse caso, é motivado pelo interesse na boa ação. A crença baseada em indícios, no primeiro argumento, é apenas um meio para a boa ação. E a extensão do argumento tentou sustentar que qualquer crença é um meio potencial para a boa ação e, por isso, deve estar baseada em indícios. Uma maneira de bloquear a extensão do argumento seria apelar para a distinção entre posse e uso. Uma coisa é ter uma crença, outra, usá-la em cognições ulteriores ou no planejamento de ações. Se respeitarmos, em relação às supostas crenças gratuitas, a norma de não usá-las como premissa em qualquer tipo de argumento, prático ou teórico, então elas não serão tomadas como meios para qualquer ação e assim elas estarão fora do escopo do primeiro argumento.

Essa é uma resposta adequada ao primeiro argumento. No entanto, ela tem de conviver com a consequência de que a posse de crenças gratuitas se torna um

\footnotetext{
${ }^{6}$ Essa estratégia, em espírito, não é muito distinta da usada por Quine, em "Dois dogmas do Empirismo" (QUINE, 1980), para sustentar a conclusão de que a matemática e a lógica também estão investidas de conteúdo empírico e, portanto, são revisáveis. Como a dedução de previsões a partir de teorias depende da lógica utilizada, a constatação de uma previsão falsa não exige necessariamente a modificação da teoria. Eventualmente, poderíamos descartar um princípio lógico para acomodar a experiência recalcitrante. É o todo da ciência, a matemática e a lógica inclusas, que tem conteúdo empírico. Analogamente, é a totalidade das crenças de um agente que tem, pelos cursos de ações que elas apoiam direta e indiretamente, consequência moral.
} 
fenômeno raro e intelectualizado. O agente só está legitimado a acalentar uma crença gratuita se tem e mantém o autocontrole de não usá-la como premissa de argumentos. Se ele quer manter crenças gratuitas, ele deve monitorá-las rigorosamente. Note ainda que ele terá talvez, se interpelado, de ser capaz de fornecer indícios de que as suas crenças gratuitas não estão sendo usadas como premissas de argumentos. O direito a crenças gratuitas parece, portanto, depender da posse de crenças não-gratuitas, isto é, baseadas em indícios, de que tais crenças gratuitas não estão sendo usadas como premissas de argumentos. Não se pode dizer que essa seja uma consequência indesejável. Muito pelo contrário, ela nos protege das possíveis consequências negativas da posse de crenças gratuitas e, portanto, inseguras. Restaria investigar empiricamente se, de fato, somos capazes de ter tal autocontrole refinado sobre as nossas crenças. Como muitos dos nossos raciocínios não são explícitos e completamente acompanhados pela reflexão ou autoconsciência, sem contudo deixarem por isso de ser raciocínios atribuíveis ao agente, crenças gratuitas poderiam muito bem participar implicitamente de raciocínios sem que o agente percebesse ou sem que ele conseguisse evitar essa participação. Se for o caso que a nossa capacidade para esse tipo de monitoramento e autocontrole é fraca ou débil, então isso poderá servir de razão, ainda que de índole consequencialista, para acatar a norma mais conservadora INDÍCIO de que devemos rejeitar qualquer crença gratuita.

\section{O INTERESSE NA VERDADE E O INIERESSE EM EVITAR O ERRO}

O segundo argumento que encontramos em Clifford apela para os nossos interesses intrinsecamente epistêmicos. Podemos nos perguntar tanto se satisfazemos diretamente o nosso interesse pela verdade através de crenças gratuitas quanto se a aceitação desse tipo de crença não tem efeitos danosos para as capacidades cognitivas, o que, por sua vez, poderia debilitar a nossa capacidade de satisfazer algum dos nossos interesses epistêmicos. ${ }^{7}$

Na primeira seção, argumentei que a própria noção de crença como um ato de tomar uma proposição como verdadeira exige pelo menos a sensibilidade a razões. Esse ato exige a aceitação de que ele mesmo é criticável, diferentemente dos gostos. Essas considerações não são ainda suficientes para sustentar que toda crença tem de estar baseada em indícios, como demanda a norma INDÍCIO. Em relação à primeira possibilidade levantada no parágrafo anterior, temos de perguntar se o ato de tomar uma proposição como verdadeira sem se basear em

\footnotetext{
${ }^{7}$ Uma maneira alternativa de interpretar o segundo argumento de Clifford, que, como veremos, explora os prejuízos causados pela credulidade, consiste em alegar que trata-se de uma obrigação moral adotar uma política de formação de crença, tal como aquela sugerida pela norma INDÍCIO, que miniminiza o risco de prejudicar alguém. Nessa leitura, que é defendida por Melissa Bergeron (2006), a obrigação moral não é de natureza consequencialista, trata-se antes de um dever. Independentemente das consequências, é categorialmente errado colocar alguém em uma situação de risco além do razoável. Para Bergeron, portanto, o fundamento para INDÍCIO seria moral. Minha leitura do segundo argumento de Clifford pressupõe apenas o nosso interesse pela verdade e explora apenas os danos epistêmicos causados pela credulidade. Portanto, minha defesa pretende oferecer um fundamento epistêmico para INDÍCIO.
} 
razões é suficiente para satisfazer o interesse pela verdade. O caso que nos interessa é o da crença gratuita, que, lembremos, é o caso de uma crença que o agente sabe não contradizer nenhuma outra crença sua baseada em razões. Se temos claro que o interesse pela verdade se distingue do interesse por evitar o erro, os nossos dois principais interesses epistêmicos, então a crença gratuita parece por si mesma satisfazer o interesse pela verdade. Em relação a uma proposição, podemos tomá-la como verdadeira, como falsa ou podemos suspender o juízo quanto a sua verdade ou falsidade. Suponha que a proposição seja verdadeira. Se a tomamos como falsa ou se suspendemos o juízo em relação a ela, então perdemos uma verdade, isto é, deixamos de contemplar uma verdade, de tê-la em mente. Se ousamos tomá-la como verdadeira, mesmo na ausência de razões ou indícios favoráveis, então ganhamos uma verdade que, de outro modo, deixaríamos escapar. Satisfazemos assim o interesse pela verdade se o entendemos como o interesse apenas na verdade pura e simples. A alegação de que esse procedimento provavelmente nos levará a tomar como verdadeiras muitas proposições que são falsas não ameaça o nosso interesse puro e simples pela verdade. Ele violará certamente o nosso interesse por evitar o erro. Como a negação de toda crença gratuita é ela mesma gratuita, a chance estimada da primeira ser verdadeira e a segunda ser falsa é igual à chance da primeira ser falsa e a segunda ser verdadeira. Assim, é de se esperar que, em relação às proposições que o agente decide tomar partido, ele erre pelo menos na metade dos casos. Contudo, desde que mantenhamos clara a diferença entre esses interesses epistêmicos, a crença gratuita é suficiente para satisfazer o interesse puro e simples na verdade. ${ }^{8}$

Se supormos que é razoável ter não apenas interesse na verdade, mas também interesse em evitar o erro, e este último é fundamental se almejamos o conhecimento ou se ao menos almejamos crenças prováveis, então crenças gratuitas não são desejáveis. Uma resposta a isso seria sustentar que o equilíbrio entre esses dois interesses possa variar de pessoa para pessoa ou de assunto para assunto. James, por exemplo, alega que esse equilíbrio depende do temperamento do agente. Pessoas ousadas e medrosas estabelecem equilíbrios diferentes entre o interesse na verdade e o interesse em evitar o erro (JAMES, 2010, p. 158). O cético é um medroso que teme errar em qualquer assunto. O religioso é uma pessoa ousada pelo menos nos assuntos religiosos e não temerá aí errar. James não chega a ser liberal a ponto de dizer que, para qualquer proposição, cabe ao agente decidir qual equilíbrio entre os dois interesses epistêmicos ele aplicará a essa proposição. A posição que ele defende é que ao menos naqueles assuntos em relação aos

\footnotetext{
${ }^{8}$ Pode-se legitimamente perguntar por que alguém teria interesse pela verdade deste modo, ou seja, preocupado apenas em não perder verdades, mas indiferente à aquisição de falsidades. Alguém que se interessa por um tipo de coisa normalmente não quer indiscriminadamente acumular instâncias desse tipo de coisa, quer também discriminá-la de outras coisas. Alguém que se interessa por ouro não quer apenas acumular ouro, mas acumular ouro sem grandes chances de acumular ouro falso também. Para fins de argumentação, estou concedendo para o defensor da legitimidade das crenças gratuitas que faça sentido ter o interesse puro e simples na verdade. Embora o interesse na verdade e o interesse em evitar o erro sejam distintos, não creio que eles possam ser completamente apartados, especialmente se o modo pelo qual nos interessamos pela verdade requer que a discriminemos da falsidade com alguma confiabilidade.
} 
quais não temos ainda qualquer perspectiva de obter conhecimento ou crenças prováveis, isto é, assuntos em relação aos quais a razão é neutra, cabe ao agente decidir se dará mais peso ao interesse na verdade ou ao interesse em evitar o erro. Em alguns assuntos, ele poderá dar peso máximo ao primeiro e mínimo ao segundo. Nesses casos, certas crenças gratuitas seriam, para esse agente, desejáveis, em harmonia com os seus interesses epistêmicos.

\section{O VÍCIO DA CREDULIDADE}

Será essa posição sustentável? Talvez essa harmonia não possa prevalecer se considerarmos os efeitos das crenças gratuitas para as capacidades cognitivas do agente como um todo. A crença gratuita é um ato de credulidade e é de se esperar que esse ato possa vir a ter efeitos sobre as nossas capacidades cognitivas. A esse respeito, Clifford alega que:

Sempre que nos permitimos acreditar por razões indignas, enfraquecemos os nossos poderes de autocontrole, de dúvida, de avaliação imparcial e honesta dos indícios (CLIFFORD, 2010, p. 106).

Antes de desenvolver o conteúdo da passagem, devemos notar que a crença gratuita resulta da capacidade de adivinhar. Entre uma proposição gratuita e a sua negação, o agente escolhe ou advinha qual é verdadeira e segue com ela. Do ponto de vista cognitivo, trata-se de uma adivinhação, de um chute, ainda que possa haver fatores emotivos que nos leve a preferir uma proposição ao invés da sua negação. A adivinhação assim concebida visa a verdade, mas não visa evitar o erro. Muitas de suas capacidades cognitivas, se não a maioria, não podem propriamente ser caracterizadas como visando apenas a verdade, elas visam também evitar o erro. Capacidades tais como a percepção, a memória, o testemunho, a razão etc. produzem ou são empregados com o objetivo de produzir episódios de conhecimento ou, quando esses não pode ser conquistados, pelo menos episódios de crenças justificadas ou baseadas em indícios. Se a aceitação de uma crença gratuita de alguma maneira compromete o emprego dessas capacidades, debilitando-as para evitar o erro, então crenças gratuitas podem, em geral, não ser desejáveis. Comprometer a capacidade de obter conhecimento ou crenças justificadas não é algo que queiramos enquanto agentes cognoscentes. Por exemplo, é sabido que somos muito sensíveis ao enviesamento de confirmação, isto é, tendemos a ignorar evidência contrária às nossas crenças e a dar maior peso à evidência favorável (NICKERSON, 1988). Se o agente incorpora crenças gratuitas, elas poderão permanecer com ele e se enraizar, apesar de ter esbarrado em evidência contrária suficiente para rejeitá-las, simplesmente por causa do enviesamento. Note ainda que ele pode esbarrar em evidência favorável, privilegiála, em detrimento da contrária, e promover uma crença gratuita para crença baseada em indícios. A partir de então, o agente poderá utilizar essa crença como premissa de argumentos, como derrogador de percepções e testemunhos etc. Ao fazê-lo, ele debilitará a capacidade de evitar o erro, relativamente ao que ele poderia evitar, se não tivesse incorporado crenças gratuitas. Por razões 
semelhantes, o poder de dúvida e de avaliação imparcial ficam emperrados se aceitamos crenças gratuitas. Se o técnico de aviação já crê de antemão que o avião está seguro, sua atenção e diligência na aplicação dos testes podem ficar enfraquecidas, se comparamos com a situação em que, de antemão, ele suspende o juízo sobre a segurança do avião. Falhas que de outro modo seriam notadas passam desapercebidas por falta de atenção e diligência. Diferentemente do caso anterior, em que se negligencia evidência desfavorável registrada, esse é um caso em que não se registra evidência desfavorável, a qual, na ausência das crenças gratuitas, o agente estaria em melhores condições de encontrar. O efeito é o mesmo: debilita-se a capacidade de evitar o erro.

Se a aceitação de uma crença gratuita reforça a disposição para aceitar outras crenças gratuitas, tornando-nos assim mais e mais crédulos, comprometemos inclusive o espaço de atuação da razão. É verdade que, se o agente respeita a demanda de não incorporar crenças que ele sabe incompatíveis com outras crenças suas baseadas em indícios, ele não vai incorporar crenças contrárias à razão. No entanto, se a sua credulidade se fortalece pela admissão de crenças gratuitas, então, sempre que a oportunidade surgir, ele preferirá exercer a adivinhação ao invés da razão para adquirir uma crença que ele ao menos sabe não contradizer outras crenças suas baseadas em indícios. A razão, na ausência de evidência para decidir, o levaria a manter a suspensão do juízo. A credulidade o faz avançar, incorporando mais e mais crenças gratuitas, tolhendo assim o espaço de atuação da razão. E uma vez adquiridas, como argumentei acima, elas podem debilitar a capacidade do agente de evitar o erro.

Um terceiro efeito da credulidade individual é que ela pode se alastrar, fomentando a credulidade coletiva. Um agente que se torna muito crédulo é alguém que não se importa muito em evitar o erro. Qualquer um que tenha consideração por esse agente perceberá nessa atitude uma razão para também não se importar muito em evitar o erro. Claro que essa razão pode ser derrogada e o argumento não é que a credulidade individual automaticamente gera a credulidade coletiva, mas apenas que lhe dá algum impulso. Além disso, o interlocutor do crédulo, percebendo que este último tem pouco interesse em evitar o erro, tem uma razão para não se importar em evitar o erro quando diz algo para o crédulo. Se este não se importa em evitar o erro, por que o seu interlocutor importaria ao falar com aquele? O crédulo, como afirma Clifford, "é o pai do batoteiro" (CLIFFORD, 2010, p. 108), o sujeito que fala bobagens, isto é, que faz alegações sem a preocupação de se o que afirma tem mais chances de ser verdadeiro do que falso.? A credulidade coletiva abala a capacidade social de evitar o erro, e a proliferação da bobagem ameaça o próprio futuro e a persistência da coletividade.

Todos esses possíveis efeitos da aquisição de crenças gratuitas devem ser investigados empiricamente. Depende de pesquisa empírica saber o quanto a atenção fica debilitada numa investigação se já acreditamos na verdade da proposição investigada, ou o quanto a disposição da credulidade é reforçada se

\footnotetext{
${ }^{9}$ Sobre o fenômeno da bobagem, seus efeitos sociais e por que ele é pior que a própria mentira, veja o iluminador ensaio de Frankfurt, Sobre falar Merda (2005).
} 
adquirimos uma crença gratuita qualquer, ou o quanto a credulidade individual reforça ou impulsiona a coletiva. E mesmo que esses efeitos não sejam negligenciáveis na maioria dos agentes, o defensor da legitimidade das crenças gratuitas poderá alegar que eles não são necessários e podem ser contornados. Desde que o agente atenda uma série de normas que visam o bloqueio desses efeitos prejudiciais à cognição, à capacidade geral do agente de evitar o erro e ao fomento da credulidade coletiva, ele estará legitimado às crenças gratuitas. Esse ponto pode ser concedido, mas note que então a legitimidade das crenças gratuitas dependeria de satisfazer algo como:

MONITORAMENTO: a crença gratuita $p$ do agente $\mathrm{S}$ é legítima se (a) S sabe que $p$ não contradiz nenhuma outra crença sua baseada em indícios, (b) $\mathrm{S}$ rastreia $p \mathrm{e}$ não a utiliza em qualquer cognição, (c) $S$ mantém durante a investigação da verdade de $p$ o mesmo nível de atenção e diligência que manteria se duvidasse de $p$, (d) S evita o enviesamento de confirmação em relação a p, (e) S evita alegar publicamente as suas crenças gratuitas ou ao menos avisa que se tratam de crenças gratuitas.

A legitimidade de crenças gratuitas, se examinada do ponto de vista puramente epistêmico, se torna algo tão intelectualizado e idealizado que, ainda que seja uma possibilidade metafísica, torna-se muito duvidoso que seja realizável por humanos como nós e que, por isso, haja qualquer interesse em defendê-la. A legitimidade de crenças gratuitas estaria melhor amparada por uma defesa que torne a posse delas plausível. Mais adiante, defenderei a legitimidade de crenças gratuitas como casos especiais de exceção à norma INDÍCIO.

\section{APRIMORANDO INDÍCIO}

$\mathrm{Na}$ medida em que a posse de crenças gratuitas debilita o emprego das capacidades cognitivas para obter conhecimento ou crenças baseadas em indícios, isto é, enfraquece a capacidade de evitar o erro, crenças gratuitas não são desejáveis, do ponto de vista epistêmico. O segundo argumento de Clifford tem um alcance geral, pois qualquer crença gratuita pode contribuir para esses efeitos indesejáveis sobre a cognição. Apenas crenças gratuitas que satisfazem MONITORAMENTO não seriam abrangidas por esse argumento, se é que seres como nós possam vir a satisfazer MONITORAMENTO.

Quando introduzi INDÍCIO, discuti como as razões morais podem contribuir para determinar quais indícios são suficientes para uma crença. A suficiência dos indícios pode ser uma função também das habilidades cognitivas do agente. Clifford não discute esse ponto em seu artigo seminal, mas me parece que ele é relevante e que a norma INDÍCIO precisa ser reformulada à luz das considerações que farei a seguir. 
Suponhamos que na semana anterior tivesse sido publicado um estudo sugerindo melhorias ao teste T5 que é aplicado às asas do avião. Essas melhorias tornariam o teste T5 ainda mais confiável, por exemplo, minimizando os falsos positivos, casos em que o avião passa no teste, mas continua apresentando a falha que o teste é elaborado para capturar. Diríamos que o técnico, que está agora examinando o avião, não reúne indícios suficientes para a crença de que o avião é seguro, uma vez que aplica o teste T5 habitual ao invés da sua versão melhorada? Se respondêssemos negativamente, então estaríamos supondo que o técnico deveria ter aplicado a versão melhorada de T5. Contudo, a mera existência dessa versão seria suficiente para tornar o técnico negligente? Suponha que a versão melhorada exige algumas operações que não eram requisitadas pelo teste habitual e que o técnico precisaria treiná-las previamente para ser capaz de aplicar a versão melhorada de T5. Nesse caso, em relação à capacidade atual do técnico de examinar a segurança do avião, parece que o técnico reuniu os indícios que ele estaria em condições de colher. Claro, a versão melhorada do teste T5 pode vir a ser homologada pelos órgãos competentes e as empresas aéreas obrigadas a aplicálo e a treinar os seus técnicos. Após o treinamento, certamente podemos e devemos reprovar o técnico se ele continua usando o teste T5 antigo ao invés da versão melhorada. De modo análogo, esperamos que os médicos com os quais consultamos estejam constantemente atualizando o seu conhecimento acerca da medicina, aprimorando as suas técnicas de diagnóstico etc. Um médico que jamais se atualiza é um que vai, só por isso, se tornando mais e mais negligente na reunião de indícios suficientes para formar os seus diagnósticos e recomendar tratamentos. No entanto, não esperamos que os médicos estejam atualizados com pesquisa de ponta publicada na semana passada, ainda que ela venha a representar melhorias para a prática médica. Essa exigência não seria razoável. Assim, parece que os indícios suficientes são sensíveis também não exatamente às capacidades efetivas que o agente tem, mas à capacidade que é razoável de se esperar que o agente tenha naquele momento. Se o técnico deixa de realizar o treinamento embora já tivesse sido alertado para fazê-lo e não tem nenhuma desculpa, então embora ele não seja atualmente capaz de reunir os indícios suficientes para crer que o avião é seguro, podemos dizer que ele estava em perfeitas condições de adquirir essa capacidade. Nesse caso, é falta dele crer que o avião é seguro sem ter adquirido a habilidade de aplicar a versão aprimorada do teste T5. É razoável esperar que ele tivesse adquirido essa habilidade. Isso torna o julgamento da suficiência dos indícios ainda mais complexa, mas não parece que esse fator possa ser negligenciado. INDÍCIO precisa ser reformulado e se o reformulamos consideramos o que já dissemos anteriormente sobre o assunto, uma sugestão seria:

INDÍCIO*: É ilegítimo para o agente $\mathrm{S}$ acreditar em $p$ com base em indícios insuficientes; os indícios reunidos pelo agente $\mathrm{S}$ são insuficientes para crer em $p$ em $t$ (i) se $\mathrm{S}$ não emprega adequadamente as capacidades, os recursos e os métodos para investigar $p$ que seriam razoáveis que $\mathrm{S}$ tivesse ao seu dispor em $t \mathrm{e}$ 
(ii) se, tendo em $t$ um curso de ação em vista que se apoia em $p$, os indícios não fazem justiça ao que está em jogo. ${ }^{10}$

Essas considerações sobre a suficiência são relevantes para explicar por que a educação científica é fundamental para a nossa sociedade. Não podemos reprovar ou condenar alguém seja por crer que simpatias têm propriedades curativas, seja por não crer que vacinas são eficientes para a prevenção de certas doenças se esse agente não tem, e não fosse esperado que tivesse, as capacidades adequadas para reunir ou ao menos compreender a evidência científica suficiente para rejeitar a primeira crença e justificar a segunda. Estaríamos agindo de modo autoritário, violando INDÍCIO* e desrespeitando o intelecto desse agente se insistíssemos que ele não deveria ter uma crença que ele tem e deveria ter outra que ele não tem mesmo na ausência da educação científica que efetivamente lhe permitiria rejeitar e adquirir respectivamente essas crenças com base em razões. Estar obrigado a crer com base em indícios não implica estar obrigado a crer com base em indícios científicos. Só a correta educação científica cria essa última obrigação.

\section{EXCEÇÕES À NORMA INDÍCIO*}

Vou ilustrar algumas ocasiões em que crenças gratuitas são legítimas. Para tanto, deve ser o caso que o bem ou benefício advindo da crença sobrepuje os malefícios produzidos pelo fortalecimento da credulidade ao se ter uma crença gratuita. Uma passagem de James ilustra bem esse tipo de ocasião:

Onde a fé num fato pode ajudar a criar esse fato, uma lógica segundo a qual a fé que se adianta aos indícios científicos é o "tipo mais baixo de imoralidade" em que um ser pensante por incorrer, seria uma lógica doente (JAMES, 2010, p. 166).

A violação de INDÍCIO* se justifica em algumas ocasiões. Por exemplo, depositar a confiança no outro antes de fazer o rastreio indutivo do quão confiável é essa pessoa é um tipo de "fé" na confiabilidade do outro que ajuda a criar esse fato. Quando demonstramos confiança no outro damos a ele uma razão para que seja confiável. Segundo James, seria doentio exigir de nós mesmos que só confiássemos no outro depois que ele se mostrasse efetivamente confiável. Doentio, pois seria contraproducente, indelicado e talvez até imoral. A promoção da confiança entre dois ou mais agentes é um bem, pelo menos prudencial, que

\footnotetext{
${ }^{10} \mathrm{Na}$ seção 4, eu já havia mencionado a dificuldade de especificar a suficiência dos indícios para o caso de proposições que são acalentadas sem se ter em vista qualquer curso de ação que se apoie nelas. Agora esses casos são contemplados pela condição (i). A proposta que faço não é livre de dificuldades e não penso que ela é muito mais precisa que a mera sugestão da suficiência dos indícios. Um passo é dado em direção ao esclarecimento ao referir à suficiência de uma prática investigativa consolidada, isso é o que tenho em mente ao falar de métodos e capacidades que seriam razoáveis que o agente tivesse. Falar de uma prática investigativa em vez de ciência é bemvindo para evitar qualquer tipo de chauvinismo.
} 
pode muito bem sobrepujar os malefícios dos atos de credulidades por meio dos quais esses agentes depositam confiança prévia entre si.

Outro exemplo. Apesar de várias pessoas conhecidas e confiáveis terem relatado para o pai que testemunharam seu filho cometendo um crime e que houvesse motivos para que o filho cometesse o crime, que ele alega não ter cometido, pode ser não só aceitável, mas moralmente requerido que o pai acredite na inocência do seu filho. Acreditar que ele é culpado seria uma violação do valor da relação de paternidade. Esse seria um caso ainda mais radical que o da crença gratuita, pois a crença acalentada, "meu filho é inocente", contradiz evidência que o agente possui e sabe possuir. A razão que justificaria essa atitude contrária à evidência é de natureza moral. Quando amamos alguém, é nosso dever confiar na pessoa amada e presumi-la inocente. Esse requerimento é ainda mais forte para o pai ou mãe, que devem cuidar e velar pela segurança emocional dos seus filhos. ${ }^{11}$ Isso não significa que os pais estejam legitimados a manter a presunção de inocência o que quer que aconteça ou qualquer que seja a evidência apresentada, apenas que a suspensão dessa presunção em relação ao filho requer muito mais razões e indícios favoráveis do que no caso que envolvesse um estranho e com o qual não se tem qualquer relação próxima ou afetiva. Honrar afetos e prestar o devido valor aos relacionamentos próximos exige uma confiança que normalmente resiste e deve resistir a um certo grau de evidência contrária a essa confiança. Em sintonia com a alegação de James, pode-se dizer que sem essa resistência o próprio relacionamento, na sua dimensão não meramente biológica ou legal, mas afetiva e moral, fica em xeque. Assim, a fé depositada no filho é necessária para criar e manter o vínculo de paternidade que valorizamos como uma autêntica relação afetiva.

Um outro tipo de exemplo seriam crenças que são habilitadoras das nossas próprias capacidades cognitivas. Por exemplo, raciocínios indutivos requerem a suposição de que de causas semelhantes seguem-se efeitos semelhantes (HUME, 2004, p. 55). Sem essa suposição, não consideraríamos a observação de várias esmeraldas verdes como suficiente para concluir que todas as esmeraldas são verdes. A capacidade de realizar raciocínios indutivos tem como condição habilitadora a suposição da uniformidade da natureza. Como não podemos colher evidência para essa suposição antes de exercer a própria capacidade de raciocinar indutivamente, temos de crer na uniformidade da natureza antes de termos indícios para ela. Sem essa crença habilitadora, todo um universo de relações causais seria deixado de fora do alcance da nossa cognição. Novamente, pode-se alegar que esse bem, ter as relações causais ao alcance da nossa cognição, sobrepuja os malefícios da credulidade. Note que está sendo alegado apenas que crenças que habilitam o exercício de uma capacidade cognitiva e, portanto, colocam ao nosso alcance cognitivo toda uma região do universo, sobrepujam os malefícios da credulidade. Apenas essas podem ser adquiridas como exceção à norma

\footnotetext{
${ }^{11}$ Por razões semelhantes, mas em sentido inverso, a mentira contada por alguém próximo é muito mais dolorosa e sentida como uma traição muito mais difícil de ser perdoada do que se fosse contada por um estranho.
} 
INDÍCIO*. ${ }^{12}$ A crença gratuita de que $p$ em particular pode muito bem, num sentido trivial, nos "habilitar" a adquirir a verdade de que $p$, se $p$ for verdadeira. Mas a não ser que tenhamos razões para pensar que a crença de que $p$ em particular encerra um bem que sobrepuja os malefícios desse ato de credulidade, não temos, prima facie, nenhuma razão para legitimar a crença gratuita de que $p$.

O ponto de James, no entanto, não pode ser generalizado, nem ele pretendeu que fosse. Em condições normais, não é legítimo se adiantar aos indícios. Crer previamente aos indícios que alguém é culpado de um crime de corrupção pode contribuir, em virtude do enviesamento de confirmação, para que se veja essa pessoa como corrupta, para que essa pessoa pareça ter o aspecto de corrupta, ou para que se tome evidência muito frágil como suficiente para sustentar que ela é corrupta. Todavia, crer previamente aos indícios que alguém é culpado de um crime não vai ajudar a criar esse fato. Neste caso, a fé que se adianta aos indícios parece ser sim um tipo baixo de imoralidade. Ao se adiantar aos indícios ou relaxar os padrões epistêmicos para crer e sustentar que alguém é culpado de um crime, aumentamos as chances de falsos positivos entre aqueles que serão tomados como culpados. Aumentamos as chances de cometer a injustiça de condenar inocentes. Esse é um caso em que o interesse pela verdade deve, por razões morais, ser controlado pelo interesse em evitar o erro.

Crenças gratuitas são assim casos especiais de exceção à norma INDÍCIO* que precisam ser justificadas. Elas têm de produzir um bem que sobrepuja os malefícios da credulidade.

\section{DUAS DIFICULDADES}

$\mathrm{Na}$ seção anterior, aleguei que a crença sem base em indícios numa proposição qualquer, embora nos habilite, em um sentido trivial, a adquirir a verdade dessa proposição se ela for verdadeira, não é razão para legitimar crenças gratuitas, pois a verdade de uma proposição qualquer não triunfa sobre a credulidade acarretada. Porém, esse último comentário poderia ser contestado pela alegação de que a crença em uma proposição serve de estímulo para o seu portador buscar meios para justificá-la ou verificá-la. A crença prévia não apenas habilitaria alguém a adquirir verdades, mas seria também um estímulo fundamental para a descoberta do que justifica essa crença. Isso poderia não só compensar, mas anular a credulidade inicialmente acarretada. Não é nenhuma novidade que o

\footnotetext{
${ }^{12}$ Clifford lida com esse caso introduzindo a distinção entre aceitação e crença. Por razões práticas, aceitamos certas proposições, como aquela que afirma a uniformidade da natureza, para tornar possível as inferências indutivas (CLIFFORD, 2010, p. 130-136). Como a norma INDÍCIO* não se aplica à aceitação, mas somente às crenças, a aceitação do princípio da uniformidade da natureza sem basear-se em razões epistêmicas para a sua verdade não seria uma violação da norma. Obviamente, ao apelar para a distinção entre aceitação e crença, além de explicá-la e fundamentála, Clifford nos deve um critério para decidir o que podemos legitimamente aceitar ou não. Caso contrário, corremos o risco de trocar uma versão do ceticismo do regresso por alguma forma de relativismo epistêmico.
} 
comprometimento de um cientista com a sua teoria é fecundo para a descoberta científica. Como salienta James,

No que interessa à descoberta tal indiferença não é tão fortemente recomendável, e a ciência estaria muito menos avançada do que está se se mantivessem fora de cena os desejos inflamados dos indivíduos em ver confirmada a sua própria fé (JAMES, 2010, p. 161).

Assim, podemos antes perder um bem, a saber, a descoberta de como justificar ou verificar a verdade de uma proposição, se nos limitamos a crer apenas após a aquisição dos indícios favoráveis e suficientes. Isso vai ainda de encontro ao que disse antes sobre como a crença prévia em uma proposição pode nos enviesar em relação à sua confirmação. O técnico de aviação, foi dito, crendo que o avião está seguro, talvez não aplique os testes com a devida diligência ou atenção. Penso que o que foi dito a respeito do técnico não precisa ser revisto. A distinção entre contexto de descoberta e contexto de justificação é útil para lidar com essa situação. No caso do técnico, ele já sabe como verificar ou justificar a proposição que afirma que um determinado avião está seguro. Ele não precisa descobrir como fazê-lo. A crença prévia na segurança do avião poderia sim muito bem desmotivar o técnico a seguir com atenção e diligência os procedimentos por meio dos quais ele pode averiguar a verdade dessa crença. Aqui a dúvida prévia, não a crença, parece ser benéfica. O caso mencionado por James é de natureza diferente. Ele pensa na situação em que o cientista ainda não sabe como determinar se a sua hipótese ou teoria é verdadeira. Neste caso, a crença prévia na hipótese ou teoria parece ser fecunda para a descoberta dos procedimentos para verificar ou justificar a hipótese ou teoria acreditada.

Parece, então, que crenças gratuitas seriam legítimas em geral na medida em que seriam conducentes à descoberta da sua própria verdade. Em resposta, tenho dois comentários a fazer. O primeiro é de que não é claro que hipóteses ou teorias acalentadas por cientistas antes que se tenha descoberto como verificá-las ou justificá-las sejam casos de crenças gratuitas. Cientistas não se comprometem com quaisquer proposições, mas com teorias ou hipóteses que são pelo menos plausíveis à luz do conhecimento de fundo da sua área de investigação. Não há ainda indícios suficientes para elas, mas certamente há indícios favoráveis, normalmente indícios que ao menos as favoreçam em relação as suas negações. O segundo comentário é que a legitimidade desse comprometimento prévio com a hipótese ou teoria na ausência de indícios suficientes se dá no contexto de investigação científica, que é muito peculiar e não pode ser confundido com o contexto cotidiano. A comunidade científica está organizada e estruturada para evitar que crenças prévias individuais de seus membros se enraízem na própria comunidade. O cientista que se compromete com uma hipótese não vai publicála antes de encontrar os indícios que julga ser suficientes para ela e seus parceiros intelectuais não legitimarão a publicação se também não julgarem que esses indícios são suficientes. Esses resultados tampouco serão utilizados como ponto de partida para investigações ulteriores antes que eles tenham sido replicados por outros pesquisadores etc. Assim, ainda que a comunidade científica possa permitir 
o comprometimento prévio individual devido a sua fecundidade para a descoberta, uma hipótese ou teoria científica só será coletivamente aceita como crível quando os indícios suficientes para ela forem encontrados. A permissão à suposta crença gratuita do cientista está condicionada a que ela só seja tomada como propriedade comum da comunidade científica depois que os seus indícios suficientes forem descobertos. Do ponto de vista da comunidade científica, INDÍCIO* prevalece. A comunidade científica internaliza assim procedimentos que anulam ou bloqueiam o que, de outro modo, fomentaria a credulidade. Fora desse contexto científico, o indivíduo teria sozinho de seguir a norma intelectualizada MONITORAMENTO para legitimar as suas crenças gratuitas.

A segunda dificuldade. Eu disse muito pouco acerca do que são os próprios indícios. Há uma dificuldade envolvendo a caracterização dos indícios que precisa ser equacionada, caso contrário a norma INDÍCIO* implicará um insustentável regresso de justificação. Se indícios são crenças do próprio agente, então a norma que exige que o agente acredite com base em indícios suficientes exige que o agente tome os próprios indícios suficientes como verdadeiros apenas se estiverem eles mesmos baseados também em indícios suficientes, os quais, por sua vez, requerem que o agente tenha também indícios suficientes para eles e assim por diante. Parece então que nenhum agente jamais estaria em condições de acreditar em qualquer coisa e a norma INDÍCIO*, se seguida à risca, nos levaria diretamente ao ceticismo. Vou indicar pelo menos duas saídas para essa dificuldade, que não são excludentes.

A primeira, como discutido na seção anterior, consiste em acatar exceções à norma INDÍCIO*, em especial, as proposições habilitadoras para o exercício de nossas capacidades cognitivas. Tais proposições serviriam como o término do regresso de justificação de qualquer outra crença que segue a norma INDÍCIO*. Isso significa que as crenças fundamentadas ou baseadas em indícios repousam sobre um fundamento que não é ele mesmo fundamentado, pelo menos não em indícios. ${ }^{13}$ Como vimos, a crença em proposições habilitadoras é justificada por razões prudenciais ou morais. A dificuldade dessa posição reside na especificação das exceções legítimas. Na ausência de um critério consensual e preciso, corremos o risco de enfrentar uma séria ameaça relativista.

A segunda consiste em apelar para a noção de experiência e sustentar que há um conjunto de crenças básicas que se apoiam diretamente nas experiências do agente. Note que tais crenças básicas não são uma exceção à norma INDÍCIO*.

\footnotetext{
${ }^{13}$ Como colocou Wittgenstein, "130. [..] Se é o fundamento para nós julgarmos assim (e não apenas a causa), continuamos sem ter fundamento para encarar isso, por sua vez, como fundamento" (1990, 49). Há bastante discussão sobre como Wittgenstein compreende o que seja o fundamento. Diferentemente da minha sugestão de tomar o fundamento como uma proposição habilitadora que é acredita por razões não-epistêmicas, alguns intérpretes de Wittgenstein sustentam que o fundamento, embora pareça ser expresso por uma proposição, não é uma proposição, mas uma ação ou modo de agir. Corrobora essa leitura as seguintes alegações de Wittgenstein: "o fim não é um pressuposto não fundamentado: é uma via de ação não fundamentada" (1990, 45), "204. [..] é o nosso atuar que está no fundo do jogo da linguagem" e "205. Se o verdadeiro é o que é fundamentado, então o fundamento não é verdadeiro nem falso" (1990, 67). Para uma discussão da posição de Wittgenstein, veja Coliva (2010).
} 
As experiências constituiriam, no caso das crenças básicas, os indícios suficientes para a crença legítima. Indícios suficientes não seriam, portanto, apenas crenças, eles compreenderiam também as experiências do agente. Essa seria a novidade da segunda saída. Como a experiência não é uma crença, o regresso da justificação é eliminado quando chegamos nas crenças básicas, e a ameaça cética é assim abortada. A dificuldade dessa posição consiste em explicar o que é a experiência, por que ela tem o estatuto de indício e, principalmente, como ela apoia ou serve de razão para uma crença. Como a experiência não é uma crença, não é claro como ela pode servir de razão para crenças. ${ }^{14}$

\section{REFERÊNCIAS BIBLIOGRÁFICAS}

ALSTON, William. The deontological conception of epistemic justification. Philosophical Perspectives, v. 2, p. 257-99, 1988.

BERGERON, Mellisa. The ethics of belief: conservative belief management. Social Epistemology, v. 20, n. 1, p. 67-78, 2006.

BORTOLLOTI, Lisa; MIYAZONO, Kengo. The ethical of delusional belief. Erkenntnis, v. 81, n. 2, p. 275-96, 2016.

CARVALHO, Eros. Crenças justificadas não-inferencialmene e o mito do dado. Princípios, v. 16, n. 25, p. 231-63, 2009.

CLIFFORD, William. A ética da crença. In: MURCHO, Desidério (ed.). A ética da crença. Lisboa: Editora Bizâncio, 2010. p. 97-136.

COLIVA, Annalisa. Moore and Wittgenstein: scepticism, certainty and common sense. New York: Palgrave Macmillan, 2010.

DESCARTES, René. Meditações sobre Filosofia Primeira. Campinas: Editora Unicamp, 2004.

FRANKFURT, Harry. Sobre falar merda. Rio de Janeiro: Editora Intrínseca Ltda., 2005.

Sobre a verdade. São Paulo: Companhia das Letras, 2007.

FRANKISH, Keith. Delusions: a two-level framework. In: BROOME, Matthew; BORTOLOTTI, Lisa. (eds.). Psychiatry as cognitive neuroscience: philosophical perspectives. Oxford: Oxford University Press, 2009. p. 269-84.

GENDLER, Tamar. Alief and belief. The Journal of Philosophy, v. 105, n. 10, p. 63463, 2008.

HUME, David. Investigação sobre o entendimento humano. São Paulo: Unesp, 2004.

Tratado da natureza humana. São Paulo: Unesp, 2009.

\footnotetext{
${ }^{14}$ Para uma discussão detalhada da dificuldade de como a experiência pode servir de razão para crer, veja o ensaio célebre de Sellars (2008) e a minha posição sobre o assunto (CARVALHO, 2009).
} 
JAMES, William. A vontade de acreditar. In: MURCHO, Desidério (ed.). A ética da crença. Lisboa: Editora Bizâncio, 2010. p. 137-74.

KORNBLITH, Hilary. On reflection. Oxford: Oxford University Press, 2012.

MACHADO, Alexandre. 2016. Toda crença não justificada é irracional? Disponível em: $\quad<$ http://problemasfilosoficos.blogspot.com.br/2013/04/toda-crencainjustificada-e-irracional.html >. Acesso em: 12 dez. 2017.

MYIAZONO, Kengo; BORTOLOTTI, Lisa. The causal role argument against doxasticism about delusions. Avant, v. 5, n. 3, p. 30-50, 2014.

NICKERSON, Raymond. Confirmation bias: a ubiquitous phenomenon in many guises. Review of General Psychology, v. 2, n. 2, p. 175-220, 1988.

QUINE, Willard. Dois dogmas do empirismo. In: PORCHAT, Oswaldo. (ed.). Os Pensadores: Quine, Ryle, Strawson, Austin. São Paulo: Abril Cultural, 1980. p. 23148.

SELLARS, Wilfrid. Empirismo e filosofia da mente. Petrópolis: Editora Vozes, 2008. SOSA, Ernest. Agency and judgment. Oxford: Oxford University Press, 2015.

STEVENSON, Leslie. Six levels of mentality. Philosophical Explorations, v. 5, n. 2, p. $105-24,2002$.

WITTGENSTEIN, Ludwig. Da certeza. Lisboa: Edições 70, 1990. 